\title{
An "acquired" hemoglobin J variant in a sickle cell disease patient
}

\author{
Nawwar Swedan' \\ Kathleen $\mathrm{Nicol}^{2}$ \\ Phylis Moder ${ }^{2}$ \\ Samir Kahwash ${ }^{2}$ \\ 'Fellow in Transfusion Medicine, \\ Ohio State University, Columbus, \\ Ohio; ${ }^{2}$ Department of Laboratory \\ Medicine, Nationwide Children's \\ Hospital, Columbus, Ohio
}

\begin{abstract}
We report the case of a rare hemoglobin variant, "Hemoglobin J", discovered while performing hemoglobin electrophoresis following exchange transfusion of a sickle cell disease patient. It is usual practice in our institution to confirm the hemoglobin $\mathrm{S}$ level in sickle cell disease patients after red cell exchange. The patient had received 5 red cell units and the source of this variant was traced back to two of those units. Due to the uncertain clinical impact of this variant, and the lack of specific guidelines, the two donors were deferred from future donations to our institution.

Keywords: hemoglobin J, sickle cell disease, transfusion
\end{abstract}

\section{Introduction}

The clinical phenotype of sickle cell disease most commonly has one of the following genotypes: $\mathrm{HbS} / \mathrm{S}, \mathrm{HbS} / \mathrm{C}$ or $\mathrm{HbS} / \mathrm{B}$ thalassemia. Less commonly, the genotype may be double heterozygous traits of hemoglobin $\mathrm{S}$ with an uncommon hemoglobin trait such as $\mathrm{Hb} \mathrm{D}, \mathrm{Hb} \mathrm{O}-\mathrm{Arab}$, or hemoglobin Lepore. The clinical impact of rare hemoglobin variants such as $\mathrm{Hb} \mathrm{J}$ when combined with hemoglobin $\mathrm{S}$ disease (or trait) is not clear in the medical literature. Many sickle cell disease patients are on chronic transfusion to prevent stroke and other complications. Routine post-transfusion testing includes hemoglobin electrophoresis, mainly to assess the level of hemoglobin S. The goal is to maintain the patient hematocrit at $25 \%$ to $30 \%$ and the proportion of $\mathrm{HbS}$ below $30 \%$ (Elghetany and Davy 2001; Brecher 2005).

\section{Case report}

A 44-year-old African American male with history of sickle cell anemia presented to our institution for scheduled red blood cell exchange transfusion. He received 5 units of red blood cells matched for $\mathrm{C}$, E, and $\mathrm{K}$ red cell phenotype.

Pre and post transfusion hemoglobin electrophoresis was performed and results revealed a new band on the electrophoretic gel, indicating the patient had "acquired" a new hemoglobin variant.

The variant band was seen in the location of $\mathrm{Hb} \mathrm{J}$ (a fast migrating variant) on isoelectric focusing (IEF) and cellulose acetate. It migrated with " $A$ " on citrate agar. The variant constituted approximately $15 \%$ of total hemoglobin.

Clinical follow up of the patient showed no complications and the clinical course was consistent with the patient's underlying medical condition.

Retained segments from the donated units were obtained and hemoglobin electrophoresis revealed two of the suspected units having hemoglobin J. Those units were donated by two sisters.

\section{Pathologic findings}

The patient's pre- and post-exchange hematological values are shown in Table 1. His pre- and post-transfusion hemoglobin electrophoresis was performed with the 
Table I Patient's pre- and post-exchange CBC results

\begin{tabular}{llll}
\hline & Pre-transfusion & Post-transfusion & Reference ranges \\
\hline RBC & 2.87 & 3.29 & $(3.9-5.3) \mathrm{M} / \mathrm{cu} \mathrm{mm}$ \\
Hb & 8.3 & 9.7 & $(11.5-13.5) \mathrm{g} / \mathrm{dL}$ \\
Hct & $24.4 \%$ & $29.1 \%$ & $(34 \%-40 \%)$ \\
RDW & $23.9 \%$ & $18.8 \%$ & $(10 \%-14.1 \%)$ \\
\hline
\end{tabular}

Abbreviations: Hb, hemoglobin; Hct, hematocrit; RBC, red blood cell; RDW, red cell distribution width.

following results: Cellulose acetate with a prominent $\mathrm{Hb} \mathrm{A}$ band, smaller band in the $\mathrm{S}$ region, and a fast hemoglobin in the position of $\mathrm{Hb} \mathrm{J}$ (Figure1). The bands on citrate agar (acid) show prominent $\mathrm{A}$ and a smaller band located in the position of S (Figure 2). IEF was done on samples from the patient blood and the 5 donated units. The variant band appeared in three samples (the patient's blood and two of the donated units), located in the position of $\mathrm{Hb} \mathrm{J}$ (these bands were more prominent in the donor's sample) (Figure 3).

The source of the variant band was apparently the 2 units of transfused blood. The donor center was notified and the transfused units were then traced to determined significant donor history, such as possible recalls of any other components.

\section{Discussion}

The human hemoglobin molecule is composed of polypeptide chains called globins, and iron-containing porphyrin rings termed heme. Every hemoglobin variant is composed of two alpha and two nonalpha globin chains, while the heme component is usually the same.

Hemoglobinopathies are a group of inherited mutations of the globin genes leading to qualitative and/or quantitative abnormalities of globin synthesis.

There are hundreds of different variants of hemoglobin caused by structural alteration of alpha, beta, or gamma globin chains varying from amino acids replacements, elongated

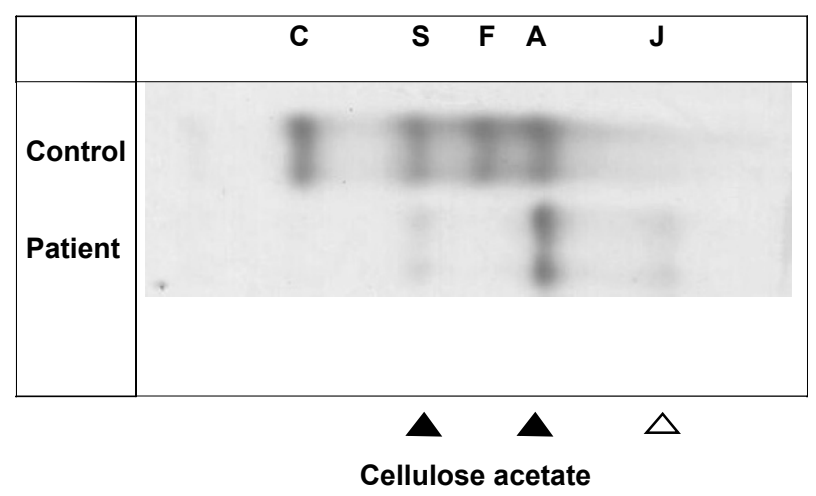

Figure I Post-red cell exchange hemoglobin electrophoresis (cellulose acetate, $\mathrm{pH}$ 8.6) of the patient showing bands at the positions of $\mathrm{Hb} \mathrm{S}, \mathrm{Hb} \mathrm{A}$, and $\mathrm{Hb}$ J.

Abbreviation: $\mathrm{Hb}$, hemoglobin.

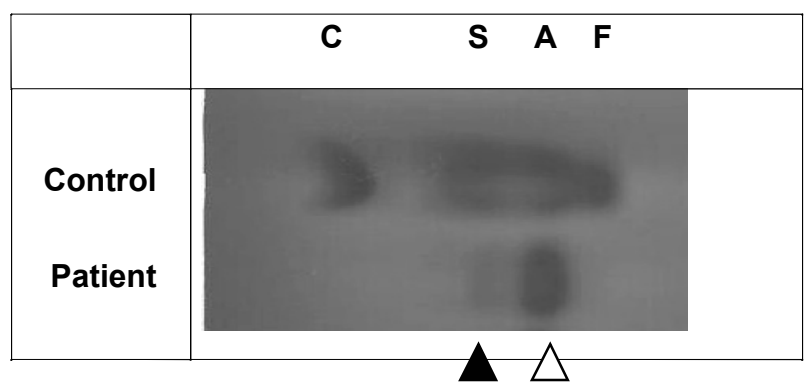

\section{Citrate agar (Acid)}

Figure 2 Post-red cell exchange hemoglobin electrophoresis (citrate agar, $\mathrm{pH} 4.6$ ) of the patient showing bands at positions $\mathrm{Hb} \mathrm{S}$ and $\mathrm{Hb} \mathrm{A}$.

Abbreviation: $\mathrm{Hb}$, hemoglobin.

chains, deletions, insertions, or both deletions and insertions (Huisman et al 1998; Elghetany and Davy 2001).

Abnormalities of beta-chain or alpha-chain produce most of the clinically significant hemoglobinopathies.

The status of zygosity also plays a very important role in the expression and detection of the disorder. In heterozygous variants the other normal allelic gene produces normal chains which may compensate for the defective gene. In the homozygous state, both allelic genes are affected which results in the production of a large amount of the variant (Scrivener et al 1985; Elghetany and Davy 2001).

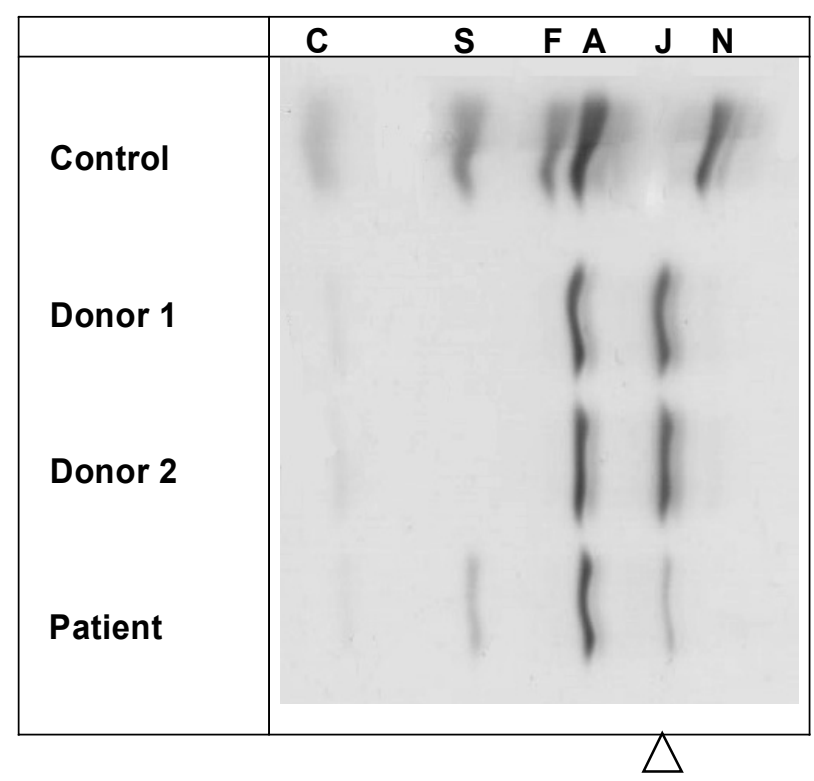

\section{Isoelectric focusing}

Figure 3 Hemoglobin electrophoresis (isoelectric focusing method) showing a band of $\mathrm{Hb} \mathrm{J}$ (arrowhead) in the patient (post-exchange) and the two red cell units from the implicated donors.

Abbreviation: $\mathrm{Hb}$, hemoglobin. 
Table 2 Patient's pre- and post-transfusion hemoglobin electrophoresis tests

\begin{tabular}{lll}
\hline & Pre-transfusion & Post-transfusion \\
\hline Hb-A & $63.0 \%$ & $71.5 \%$ \\
Hb-A2 & $3.5 \%$ & $2.0 \%$ \\
Hb-S & $33.5 \%$ & $11.0 \%$ \\
Hb variant & None & $15.5 \%$ \\
\hline
\end{tabular}

Abbreviation: $\mathrm{Hb}$, hemoglobin.

The vast majority of hemoglobin variants are encountered in the heterozygous state and most individuals carrying these variants have a completely normal physical picture and normal hematological tests. In the US, most hemoglobin variants are diagnosed in early childhood. This is mainly a benefit of newborn screening which began in the 1980's and is currently conducted in at least 44 states.

One of the most common hemoglobinopathies is sickle hemoglobin $(\mathrm{Hb} \mathrm{S})$, which is responsible for the sickle cell disease and trait. The molecular nature of this hemoglobin variant is a substitution of valine for glutamic acid at the sixth amino acid position in the beta globin gene, which results in decreased solubility of $\mathrm{Hb}$, causing red cells to sickle (Suarez et al 1999; Elghetany and Davy 2001).

Most hemoglobinopathies are prevalent in tropical regions, perhaps due to the advantage of the heterozygote state in areas where malaria is endemic. Malaria parasites live inside red blood cells, but subtly disturb normal cellular function. In patients predisposed to rapid clearance of red blood cells, this may lead to early destruction of cells infected with the parasite and increased chance of survival for the carrier of the trait.

The prevalence of $\mathrm{Hb} \mathrm{S}$ in the US is mainly in people from African or Hispanic descent. Sickle trait has a prevalence of 8\%-10\% among African Americans. Approximately 1/500 African Americans and 1/1000 Hispanics have sickle cell anemia.

The prevalence of hemoglobin variants among blood donors is unknown, as no hemoglobin electrophoresis is routinely performed on donated units.

We are aware of only a few articles in the literature describing hemoglobin variants acquired through transfusion (Gibaud et al 1974; Rechavi et al 1986; Strobel et al 1987; Robertson et al 1997; Suarez et al 1999).

To our knowledge there is no reported case in the literature of transfusion-acquired hemoglobin J.

There are more than 50 hemoglobin J variants described in the literature. For example, Hb-J Capetown (alpha92(FG4) Arg->Gln), Hb-J Buda (alpha61(E10)Lys->Asn), Hb-J
Chicago (beta76(E20)Ala- $>$ Asp), Hb-J Sardegna (alpha50(CE8) His- $>$ Asp), and Hb-J Toronto 9 alpha5(A3)Ala- $>$ Asp), etc. They all have an electrophoretic mobility "faster" than " $\mathrm{A}$ " on cellulose acetate (ie, close to the anode) in common. All are classified under "variants of the alpha- or beta-chains" (single or multiple base changes), or "hemoglobins with more than one amino acid substitution in the alpha chain" (eg, J-Singapore (alpha78(EF7)Asn->Asp) (Botha et al 1966; Lambridis et al 1986; stidda et al 2002).

One recently described hemoglobin $\mathrm{J}$, found in a few members of an Italian family, named $\mathrm{Hb}$ J-Europa has a beta chain substitution (beta62(E6)Ala->Asp) (Huisman et al 1998).

Hemoglobin J (depending on its type) has different characteristics and functions. For example hemoglobin J Capetown $\left(\alpha 2{ }^{92 \mathrm{Gln}} \beta 2\right.$ ), the most commonly seen $\mathrm{Hb} \mathrm{J}$ variant (CGG$>\mathrm{CAG})$, is associated in the heterozygous state with increased oxygen affinity and polycythemia. Those affected may also have a mild erythrocytosis and microcytosis (Botha et al 1966; Elghetany and Davy 2001). Other variants like Hb J Sardegna will show a completely unremarkable clinical picture in the heterozygote. Hemoglobin J Bancock (beta 56 Gly->Asp) and J Baltimore (beta 16 Gly->Asp) have been described in combination with sickle hemoglobin. These individuals of African descent were reportedly clinically asymptomatic, however, as a double heterozygote there may be the potential of sickle cell trait-like complications (Gellady and Schwartz 1973; Gunay et al 1974; Weatherall 1974).

In this particular case, review of the history of the two blood donors revealed them to be sisters with no significant past medical history (which would have deferred them as donors initially). These sisters, 81- and 83-year-old Caucasian women, from French, German, and English descent had a long history of blood donation (more than 15 donations each, starting in 1997). They were unaware of having this hemoglobin variant and were not aware of any abnormalities in their family (parents and 3 siblings).

There were no transfusion-associated adverse events reported in any of the recipients of their previously donated red blood cells, nor in the patient who received the current units. Further characterization of this hemoglobin variant was not indicated clinically, so molecular studies were not pursued.

The decision to defer the donors was made at the discretion of the medical director of our blood donor center. This decision is admittedly open for questions and debate as there are currently no specific guidelines or policies in the medical literature for accepting or deferring donors after discovering 
a rare hemoglobin variant. We hope that this case report will stimulate discussions that will lead to specific guidelines.

\section{Acknowledgment}

The authors would like to thank Barbara Grooms for her administrative assistance in preparing this manuscript for publication.

\section{References}

Elghetany MT, Davy FB. 2001. Erythrocytic disorders. In: Henry JB (ed). Clinical Diagnosis and Management by Laboratory Methods. 12th Ed. W. Syracuse, New York: B Saunders Co, pp. 561-3.

Botha MC, Beale D, Isaacs WA, et al. 1966. Hemoglobin J Cape Town-alpha-2 92 arginine replaced by glutamine beta-2. Nature, 212:792-5.

Gellady AM, Schwartz AD. 1973. Hemoglobin S and J coexisting in the same family. J Pediatr, 83:1038-40.

Gibaud A, Braconnier F, Garel MC, et al. 1974. An acquired S hemoglobin in the adult. Nouv Presse Med, 3:2013-14.

Gunay U, Pauli C, Shamsuddin M, et al. 1974. Sickle hemoglobin in combination with $\mathrm{HbJ}^{\mathrm{Bangkok}}\left(\alpha_{2}^{\mathrm{A}} \beta_{2}{ }^{56 \text { gly } \rightarrow \text { asp }}\right)$. Blood, 44:683-90.
Huisman TH, Carver MF, Efremov GD. 1998. A Syllabus of Human Hemoglobin Variants. 2nd Ed. Augusta, GA: The Sickle Cell Anemia Foundation.

Lambridis AJ, Ramsay M, Jenkins T. 1986. The haematological puzzle of $\mathrm{Hb} \mathrm{J}$ (Cape Town) is partly solved. Br J Haematol, 63:363-7.

Pistidda P, Guiso L, Frogheri L, et al. 2002. The homozygous state of $\mathrm{Hb}$ J Sardegna. Hematol J, 3:176-8.

Rechavi G, Brok-Simoni F, Ben-Bassat I, et al. 1986. Spurious haemoglobinopathy. Lancet, 1:1035.

Robertson PB, Danielson CFM, McCarthy LJ. 1997. Unexpected hemoglobin electrophoresis results following red cell exchange in a sickle cell anemia patient with acute chest syndrome. Transfus Sci, 18:195-8.

Scriver CR, Beaudet AL, Sly WS, et al. (eds). 1985. The Metabolic Basis of Inherited Disease, $7^{\text {th }}$ Ed. New York, NY: McGraw-Hill, pp. 3430-9.

Strobel SL, Panke TW, Zelenski K. 1987. Hemoglobin C acquired via a blood transfusion. Detection by automated blood counter. Arch Pathol Lab Med, 111:565-8.

Suarez A, Polski J, Grossman B, et al. 1999. Blood transfusion-acquired hemoglobin C. Arch Pathol Lab Med, 642-3.

Brecher, M. 2005. Technical manual: AABB (Technical Manual of the American Association of Blood Banks). $15^{\text {th }}$ Ed. Bethesda, MD, AABB, pp. 508-9.

Weatherall DJ. 1964. Hemoglobin J (Baltimore) coexisting in a family with hemoglobin S. Johns Hopkins Med J, 114:1-12. 